\title{
The impact of ginsenosides on cognitive deficits in experimental animal studies of Alzheimer's disease: a systematic review
}

\author{
Chenxia Sheng ${ }^{1,2,3}$, Weijun Peng ${ }^{1}$, Zi-an Xia ${ }^{2,3}$, Yang Wang ${ }^{2,3}$, Zeqi Chen ${ }^{2,3}$, Nanxiang Su ${ }^{1}$ and Zhe Wang ${ }^{\text {* }}$
}

\begin{abstract}
Background: The efficacy of ginsenoside treatment on cognitive decline in individuals with Alzheimer's disease (AD) has yet to be investigated. In this protocal, we conducted a systematic review to evaluate the effect of ginsenosides on cognitive deficits in experimental rodent AD models.

Methods: We identified eligible studies by searching seven electronic databases spanning from January 1980 to October 2014. We assessed the study quality, evaluated the efficacy of ginsenoside treatment, and performed a stratified meta-analysis and meta-regression analysis to assess the influence of the study design on ginsenoside efficacy.

Results: Twelve studies fulfilled our inclusion criteria from a total of 283 publications. The overall methodological quality of these studies was poor. The meta-analysis revealed that ginsenosides have a statistically significant positive effect on cognitive performance in experimental AD models. The stratified analysis revealed that ginsenoside Rg1 had the greatest effect on acquisition and retention memory in AD models. The effect size was significantly higher for both acquisition and retention memory in studies that used female animals compared with male animals.
\end{abstract}

Conclusions: We conclude that ginsenosides might reduce cognitive deficits in AD models. However, additional welldesigned and well-reported animal studies are needed to inform further clinical investigations.

\section{Background}

Alzheimer's disease (AD), the incidence of which is rapidly increasing worldwide, leads to death within 3 to 9 years after diagnosis. It has been estimated that the number of individuals living to 100 years or more will increase by over $200 \%$ and that the number of individuals surviving to $90-95$ years will double between 2000 and 2020 [1]. One of the most significant disabilities associated with AD is cognitive impairment [2]. This impairment interferes with work, relationships, leisure, and activities of daily living and exacts a personal and economic cost that is difficult to quantify. In addition, cognitive impairment in $\mathrm{AD}$ is associated with a significant social burden and time commitment on the caregiver [3].

$\mathrm{AD}$ is characterized by three neuropathological hallmarks: neuronal loss, senile plaques (SPs), and

\footnotetext{
* Correspondence: ericwangzhe@126.com

'Department of Integrated Chinese and Western Medicine, The Second Xiangya Hospital, Central South University, No.139 Middle Renmin Road, Changsha, Hunan 410011, PR China

Full list of author information is available at the end of the article
}

neurofibrillary tangles (NFTs) [4, 5]. SPs predominantly consist of extracellular amyloid $\beta$ peptide $(A \beta)$, which is the key protein that induces neuronal damage and apoptosis in AD patients $[6,7]$. NFTs are formed by intraneuronal aggregation of hyperphosphorylated tau [8]. Few therapeutic options to prevent or alleviate cognitive deficits in AD exist [9].

Ginseng, the root of Panax ginseng C.A. Meyer, is a traditional medicinal herb that has been applied widely in Asia for the treatment of aging and memory deterioration [10]. Ginsenosides such as ginsenoside Rg, ginsenoside $\mathrm{Rb}$, and ginsenoside $\mathrm{Re}$ are the most important pharmacologically active ingredients in ginseng [11]. Ginsenosides are a class of tetracyclic triterpene glycosides (also known as saponins) [12] that are widely used in herbal medicine and have been shown to attenuate cognitive impairment and improve behavioral symptoms in humans [13]. Recent studies have demonstrated that the long-term consumption of ginsenoside Rg1 improves cognitive performance, decreases the levels of $\mathrm{A} \beta_{1-42}$ protein in the hippocampus of aged senescence-accelerated 
mouse prone 8 (SAMP8) [14], decreases the accumulation of NFTs [15], increases the extracellular secretion of soluble amyloid precursor protein $\alpha$ (sAPP $\alpha)$, and enhances $\alpha$-secretase activity [16]. Rb1 protects neurons against $\mathrm{A} \beta_{1-42}$-induced neurotoxicity and tau hyperphosphorylation [17]. Furthermore, ginsenoside Rh2 reduces senile plaques and plays an important role in neuronal differentiation [18]. Ginsenoside Rd has been shown to alleviate inflammation and alleviate cognitive deficits [19].

The need to conduct systematic reviews of animal experiments, which can provide evidence for the potential translational value of animal models to human disease, has been highlighted [20]. Systematic reviews and metaanalyses of animal studies contribute to the modeling of clinically relevant problems; in particular, such reviews allow decisions regarding the design and conduct of subsequent clinical trials to be based on all existing evidence synthesized in an unbiased manner. Moreover, systematic reviews permit a more objective appraisal of evidence than is allowed by the traditional narrativestyle reviews that are more commonly associated with animal research [21]. However, there are few systematic randomized trials and observational studies that have explored the effect of ginsenosides on cognition in humans with AD. Therefore, a meta-analysis was conducted to evaluate the efficacy of ginsenosides for the treatment of cognitive impairment in experimental animal models of $\mathrm{AD}$ and explore the impact of the study design and quality on the reported outcomes.

\section{Methods}

\section{Literature search}

In October 2014, seven electronic databases (PubMed, Web of Science, MEDLINE, Embase, Google Scholar, CNKI, and Wanfang) were searched using the terms "Alzheimer's disease" (or "dementia", "Alzheimer disease", "Alzheimer", "Alzheimer's", "Alzheimers") and "ginsenoside" (or "ginseng, "ginseng saponin"). All the searches were limited to literature published between January 1980 and October 2014. This systematic review was limited to the results of animal studies. The reference lists from relevant publications were used to identify further relevant research articles and reviews. Each study had to meet several inclusion criteria (Table 1) to be included in this meta-analysis. To determine their eligibility for inclusion, two investigators (Chenxia Sheng and Weijun Peng) assessed the titles and abstracts of identified articles, and obtained copies of the articles to review the study design and methodology for studies that administered ginsenoside and measured cognitive, behavioral, and motor problems in AD model rodents. Disagreements among the investigators were resolved by consensus following a discussion.

\section{Data extraction}

Two investigators extracted information about the studies, including the species; sample size; type of AD model; main experimental groups; type of anesthetic agent; substances used as experimental and control treatments; the dose, method, and timing of ginsenoside administration; and the time of the outcome assessment.

The Morris water maze (MWM) was used to assess cognition in all the studies included in the analysis. If cognition was assessed several times in the study, then only the final assessment was included in the analysis. For cases in which the data were expressed graphically, the investigators attempted to obtain numerical values from the study authors; if these values were not available, then digital ruler software was used to estimate the numerical values from the graphs. For cases in which the data were missing, the investigators contacted the authors and requested the additional information. If the required data were not available, then the study was excluded from the analysis. If one study examined different animal models of $\mathrm{AD}$ or ginsenoside doses, then these models or doses were analyzed as separate studies.

\section{Methodological quality}

The methodological quality of the studies was assessed based on a checklist modified from the Collaborative Approach to Meta-Analysis and Review of Animal Data

Table 1 Criteria for study inclusion/exclusion

\begin{tabular}{ll}
\hline Inclusion criteria & Exclusion criteria \\
\hline (1) Ginsenoside were administered. & (1) Ginsenoside were not administered. \\
$\begin{array}{ll}\text { (2) Experimental AD was induced in rodents (i.e., rats or mice). } & \text { (2) Other types of animals (e.g., sheep, cats, and dogs) were used. } \\
\text { (3) AD treatment group was treated with a pharmacological agent, and a control } & \text { (3) Treatment group was administered another neuroprotective } \\
\text { group was administered a placebo after injury. } & \text { agent in addition to ginsenoside. } \\
\text { (4) Cognitive function was measured by the MWM. } & \text { (4) Treatment group was administered another Chinese } \\
\text { (5) Article was published in English or Chinese language. } & \begin{array}{l}\text { Traditional medicine in addition to ginsenoside. } \\
\end{array} \\
& \text { (5) Only biochemical or physiological outcomes of treatment } \\
& \text { efficacy were assessed. }\end{array}$ \\
\hline
\end{tabular}


from Experimental Studies (CAMARADES), as previously described [22] with minor modifications. The modified CAMARADES included randomization of subjects into treatment groups instead of blinded induction of ischemia (allocation concealment) [23]. One point was tallied for written evidence of each of the following criteria: peer-reviewed publication; randomization of subjects into treatment groups; assessment of dose-response relationship; blind assessment of behavioral outcomes; monitoring of physiological parameters, such as body temperature; calculation of the sample size necessary to achieve sufficient power; statement of compliance with animal welfare regulations; avoidance of anesthetic agents with marked intrinsic neuroprotective properties (e.g., ketamine); statement of potential conflicts of interest; and use of a suitable animal model (Table 2).

The study quality also was assessed with secondary criteria as previously described [24] (Table 3). These criteria included study characteristics such as the age, species, and sex of the animals used; the duration of supplementation; and the dose(s) of ginsenoside. These criteria also included an assessment of the internal validity of the study, i.e., performance bias (differences in care provided?); exclusion bias (differences in withdrawal from studies?); detection bias (differences in outcome measurements?); and selection bias (differences in allocation to comparison groups?), as well as an assessment of the external validity of the population, intervention, and outcome.

\section{Statistical analysis}

All statistical analyses were conducted in accordance with the Cochrane Handbook for Systematic Reviews of Interventions. For each outcome measure in each study, the standardized mean difference (SMD; equal to the difference in the mean outcome between the groups divided by the standard deviation of the outcomes among the participants, which was reported in units of standard deviation) was calculated, which allows data measured on different scales to be merged. Despite the anticipated heterogeneity, the individual SMDs were pooled whenever possible to obtain an overall SMD and $95 \%$ confidence intervals $(\mathrm{CI})$.

Within- and between-study heterogeneity or variation was assessed using Cochran's Q-statistic. A significant Q-statistic (i.e., $p<0.10$ ) indicated heterogeneity among studies. Heterogeneity also was assessed using the metric of Cochran's Q-statistic, $\mathrm{I}^{2}$ values of 25,50 and $75 \%$ correspond to low, medium and high levels of heterogeneity, respectively; values $\leq 50 \%$ indicated an acceptable degree of heterogeneity between studies [25].

The presence of small-study effects was investigated with funnel plots and Egger tests. A $p<0.10$ on the
Egger test indicated the presence of small-study effects. For studies comparing different doses or timing of drug administration to a single control group, the data from all experimental groups were pooled to compare with the control group. The pooled effect size was estimated using fixed- and random-effects models. When there was heterogeneity among studies, the pooled effect size was estimated using a randomeffects model.

Both biological and methodological characteristics were examined in an attempt to explain the possible causes of heterogeneity (i.e., the possible causes modifying the outcome) among the studies. Stratified analyses were performed with experiments grouped according to the following characteristics: species and sex of the animals; anesthetic method; type and dose of ginsenoside; study quality; and the route of drug delivery. The difference between the groups was assessed by partitioning the heterogeneity and using the $X^{2}$ distribution with $n-1$ degrees of freedom (df), where $n$ equals the number of groups. To adjust the significance levels for multiple comparisons, we used a Bonferroni correction [26] [declared significance $=$ 1 - $(1 \text { - denoted significance })^{\wedge}(1 /$ number of comparisons $\left.)\right]$, yielding critical p-values of 0.00215 for the acquisition memory and 0.00394 for the retention memory.

Finally, the impact of several variables (i.e., species and sex of the animals; anesthetic method; type and dose of ginsenoside; study quality; and the route of drug delivery) on the efficacy of ginsenoside was assessed using meta-regression when substantial or considerable heterogeneity existed.

All statistical analyses were performed using Stata software (version 13.0, College Station, Texas, USA) and Review Manager (version 5.3).

\section{Results}

Study inclusion

A total of 281 publications were identified, of which 13 met our inclusion criteria [18, 27-38]. Of these 13 publications, one [18] was excluded from further analysis because too few data were available to assess in the meta-analysis. Therefore, this meta-analysis is based on 12 studies, which included 24 comparisons of acquisition memory and 13 comparisons of retention memory (Fig. 1).

\section{Study characteristics}

Of the 12 included studies (Table 4), four were published in Chinese academic journals and 8 were published in English academic journals. The A $\beta$-induced $A D$ model was the most frequently used animal model of $\mathrm{AD}[30-33,35$, 37]. Of the 12 studies, four used non-transgenic mice [27, 31, 35, 37], 4 used Sprague-Dawley rats [28-30,36], and four used Wistar rats [32-34, 38]. Six studies used male animals only [27-30, 32, 36], and three studies used 
Table 2 Characteristics of included studies

\begin{tabular}{|c|c|c|c|c|c|c|c|}
\hline Study & Animal species & AD model & Main experimental groups & $\begin{array}{l}\text { Method of } \\
\text { administration }\end{array}$ & $\begin{array}{l}\text { Time of ginsenoside } \\
\text { administration }\end{array}$ & $\begin{array}{l}\text { Anesthetic } \\
\text { agent }\end{array}$ & $\begin{array}{l}\text { Duration of } \\
\text { supplementation }\end{array}$ \\
\hline \multirow{4}{*}{$\begin{array}{l}\text { Wang YC et al. } \\
2014\end{array}$} & \multirow{4}{*}{$\begin{array}{l}\text { Male Kunming } \\
\text { mice }\end{array}$} & \multirow[t]{4}{*}{ chronic restraint stress (CRS) } & Control $r(n=15)$ & \multirow[t]{4}{*}{$\lg$} & \multirow[t]{4}{*}{ Immediately after injury } & \multirow{4}{*}{$\begin{array}{l}\text { chloral } \\
\text { hydrate }\end{array}$} & \multirow[t]{4}{*}{8 weeks } \\
\hline & & & CRS + distilled water $(n=15)$ & & & & \\
\hline & & & CRS $+2.0 \mathrm{mg} / \mathrm{kg} \operatorname{Rg} 1(n=15)$ & & & & \\
\hline & & & CRS +5.0 mg Rg1 / kg r $(n=15)$ & & & & \\
\hline \multirow{4}{*}{$\begin{array}{l}\text { Bombi Lee et al. } \\
2013\end{array}$} & \multirow[t]{4}{*}{ Male SD rats } & \multirow{4}{*}{$\begin{array}{l}\text { LPS injected into the bilateral } \\
\text { lateral cerebral ventricle }\end{array}$} & LPS-injected plus saline $(n=6)$ & \multirow[t]{4}{*}{ Ip } & \multirow[t]{4}{*}{ Immediately after injury } & \multirow[t]{4}{*}{ pentobarbital } & \multirow[t]{4}{*}{3 weeks } \\
\hline & & & LPS-injected plus 10 mg/kg Rg3 $(n=6)$ & & & & \\
\hline & & & LPS-injected plus 20 mg/kg Rg3 $(n=6)$ & & & & \\
\hline & & & LPS-injected plus 30 mg/kg Rg3 $(n=6)$ & & & & \\
\hline \multirow{4}{*}{$\begin{array}{l}\text { Song } X Y \text { et al. } \\
2013\end{array}$} & \multirow[t]{4}{*}{ Male SD rats } & \multirow{4}{*}{$\begin{array}{l}\text { OKA injected into the right } \\
\text { lateral cerebral ventricle }\end{array}$} & OKA-injected plus distilled water $(n=12)$ & \multirow[t]{4}{*}{$\lg$} & \multirow{4}{*}{$\begin{array}{l}\text { A week before OKA } \\
\text { microinjected }\end{array}$} & \multirow{4}{*}{$\begin{array}{l}\text { chloral } \\
\text { hydrate }\end{array}$} & \multirow[t]{4}{*}{25 days } \\
\hline & & & OKA-injected plus 5 mg/kg Rg1 $(n=12)$ & & & & \\
\hline & & & OKA-injected plus 10 mg/kg Rg1 $(n=12)$ & & & & \\
\hline & & & OKA-injected plus 20 mg/kg Rg1 $(n=12)$ & & & & \\
\hline \multirow{2}{*}{$\begin{array}{l}\text { Quan QK et al. } \\
2013\end{array}$} & \multirow[t]{2}{*}{ Male SD rats } & \multirow{2}{*}{$\begin{array}{l}\text { A } \beta 1-42 \text { injected into Both } \\
\text { Hippocampal CA1 regions }\end{array}$} & A $\beta 1-42$ injected plus normal saline $(n=10)$ & \multirow[t]{2}{*}{ Ip } & \multirow[t]{2}{*}{5 days after $A \beta 1-42$ injected } & \multirow{2}{*}{$\begin{array}{l}\text { chloral } \\
\text { hydrate }\end{array}$} & \multirow[t]{2}{*}{4 weeks } \\
\hline & & & $A \beta 1-42$ injected plus $10 \mathrm{mg} / \mathrm{kg} \operatorname{Rg} 1(n=10)$ & & & & \\
\hline \multirow{2}{*}{$\begin{array}{l}\text { Zhao HH et al. } \\
2012\end{array}$} & \multirow{2}{*}{$\begin{array}{l}\text { Female ICR } \\
\text { mice }\end{array}$} & \multirow[t]{2}{*}{ Oral $\mathrm{AlCl} 3$ in drinking water } & Al exposure plus distilled water $(n=8)$ & $\lg$ & 6 month after $\mathrm{AlCl} 3$ oraled & pentobarbital & 4 months \\
\hline & & & Al exposure plus 20 mg/kg Rb1 $(n=8)$ & & & & \\
\hline Wang YL et al. & Male Wistar rats & $A \beta 1-40$ into the right lateral & A $\beta 1-42$ plus saline $(n=10)$ & Ip & 2 weeks after $\mathrm{AlCl} 3$ orale & not clear & 4 weeks \\
\hline & & & A1-42 plus $10 \mathrm{mg} / \mathrm{kg} \operatorname{Rg} 2(n=10)$ & & & & \\
\hline Zhang $X$ et al. & Female Wistar & Ovariectomized (OVX) \& & OVX, D-gal plus vehicle & Ip & Immediately after injury & chloral & 6 weeks \\
\hline & & D-gal injected intraperitoneally & OVX, D-gal plus 5 mg/kg Rg1 $(n=8)$ & & & & \\
\hline & & & OVX, D-gal plus 10 mg/kg Rg1 $(n=8)$ & & & & \\
\hline & & & OVX, D-gal plus 20 mg/kg Rg1 $(n=8)$ & & & & \\
\hline Chu SH et al. 2014 & Wistar rats & Streptozotocin (STZ) injected & STZ plus physiological saline $(n=12)$ & $\lg$ & 2 days after STZ injected & not clear & 4 weeks \\
\hline & & $\begin{array}{l}\text { Into the bilateral lateral cerebral } \\
\text { ventricle }\end{array}$ & STZ plus $5 \mathrm{mg} / \mathrm{kg} \operatorname{Rg} 5(n=12)$ & & & & \\
\hline & & & STZ plus 10 mg/kg Rg5 $(n=12)$ & & & & \\
\hline & & & STZ plus 20 mg/kg Rg5 ( $n=12)$ & & & & \\
\hline Zhou LP et al. 2011 & $\begin{array}{l}\text { Female C57BL/6 } \\
\text { mice }\end{array}$ & $\begin{array}{l}\text { Ovariectomized }(\mathrm{OVX}) \& A \beta_{25-35} \\
\text { injected into the lateral cerebral } \\
\text { ventricle }\end{array}$ & OVX, Aß 25-35 plus Rg1 10 mg/kg $(n=10)$ & Ip & 10 days later & $\begin{array}{l}\text { chloral } \\
\text { hydrate }\end{array}$ & 14 days \\
\hline $\begin{array}{l}\text { Wang } X Y \text { et al. } \\
2001\end{array}$ & $\begin{array}{l}\text { Male Kunming } \\
\text { mice }\end{array}$ & $\begin{array}{l}\mathrm{A} \beta_{25-35} \text { injected into the lateral } \\
\text { cerebral ventricle }\end{array}$ & A 25 -35 plus physiological saline $(n=10)$ & Ip & 1 days after $A \beta 25-35$ injected & diethyl ether & 10 days \\
\hline
\end{tabular}


Table 2 Characteristics of included studies (Continued)

Wu W et al. 2011 Male SD rats fimbria/fornix transection

fimbria/fornix transection(15)

fimbria/fornix transection plus

$10 \mathrm{mg} / \mathrm{kg} \operatorname{Rg} 1(n=15)$

Zang $Y$ et al. 2010 Male \& female $\quad A \beta_{25-35}$ injected into Both

Wistar rats

Hippocampal regions

A $25-35$ plus physiological saline $(n=12)$

A $325-35$ plus $3 \mathrm{mg} / \mathrm{kg} \operatorname{Rg} 2(n=12)$

Aß25-35 plus $6 \mathrm{mg} / \mathrm{kg} \operatorname{Rg} 2(n=12)$

A $325-35$ plus $12 \mathrm{mg} / \mathrm{kg} \operatorname{Rg} 2(n=12)$

$\lg$ intragastrically, Ip intraperitoneally 
Table 3 The CAMARADES quality items

\begin{tabular}{|c|c|c|c|c|c|c|c|c|c|c|c|}
\hline Study & (1) & (2) & (3) & (4) & (5) & (6) & (7) & (8) & (9) & (10) & Quality score \\
\hline Wang YC et al. 2014 & $\sqrt{ }$ & $\sqrt{ }$ & $\sqrt{ }$ & & $\sqrt{ }$ & & $\sqrt{ }$ & $\sqrt{ }$ & & $\sqrt{ }$ & 7 \\
\hline Bombi Lee et al. 2013 & $\sqrt{ }$ & $\sqrt{ }$ & $\sqrt{ }$ & $\sqrt{ }$ & $\sqrt{ }$ & & $\sqrt{ }$ & $\sqrt{ }$ & & $\sqrt{ }$ & 8 \\
\hline Song XY et al. 2013 & $\sqrt{ }$ & $\sqrt{ }$ & $\sqrt{ }$ & & & & $\sqrt{ }$ & $\sqrt{ }$ & & $\sqrt{ }$ & 6 \\
\hline Quan QK et al. 2013 & $\sqrt{ }$ & $\sqrt{ }$ & & & & & $\sqrt{ }$ & $\sqrt{ }$ & $\sqrt{ }$ & $\sqrt{ }$ & 6 \\
\hline Zhao HH et al. 2012 & $\sqrt{ }$ & $\sqrt{ }$ & & & & & $\sqrt{ }$ & $\sqrt{ }$ & $\sqrt{ }$ & $\sqrt{ }$ & 6 \\
\hline Wang YL et al. 2010 & $\sqrt{ }$ & $\sqrt{ }$ & & & $\sqrt{ }$ & & & $?$ & & $\sqrt{ }$ & 4 \\
\hline Zhang X et al. 2012 & $\sqrt{ }$ & $\sqrt{ }$ & $\sqrt{ }$ & & $\sqrt{ }$ & & $\sqrt{ }$ & $\sqrt{ }$ & $\sqrt{ }$ & $\sqrt{ }$ & 8 \\
\hline Chu SH et al. 2014 & $\sqrt{ }$ & & $\sqrt{ }$ & & & & $\sqrt{ }$ & $?$ & & $\sqrt{ }$ & 4 \\
\hline Zhou LP et al. 2011 & $\sqrt{ }$ & $\sqrt{ }$ & & & & & & $\sqrt{ }$ & & $\sqrt{ }$ & 4 \\
\hline Wang XY et al. 2001 & $\sqrt{ }$ & $\sqrt{ }$ & $\sqrt{ }$ & & & & $\sqrt{ }$ & $\sqrt{ }$ & & $\sqrt{ }$ & 6 \\
\hline Wu W et al. 2011 & $\sqrt{ }$ & $\sqrt{ }$ & & & & & & $\sqrt{ }$ & & $\sqrt{ }$ & 4 \\
\hline Zang Y et al. 2010 & $\sqrt{ }$ & $\sqrt{ }$ & $\sqrt{ }$ & & & & & $\sqrt{ }$ & & $\sqrt{ }$ & 5 \\
\hline
\end{tabular}

(1) peer reviewed publication; (2) presence of randomization of subjects into treatment groups; (3) assessment of dose-response relationship; (4) blinded assessment of behavioural outcome; (5) monitoring of physiological parameters such as body temperature; (6) calculation of necessary sample size to achieve sufficient power; (7) statement of compliance with animal welfare regulations; (8) avoidance of anaesthetic agents with marked intrinsic neuroprotective properties (e.g., ketamine); (9) statement of potential conflict of interests; (10) use of a suitable animal model

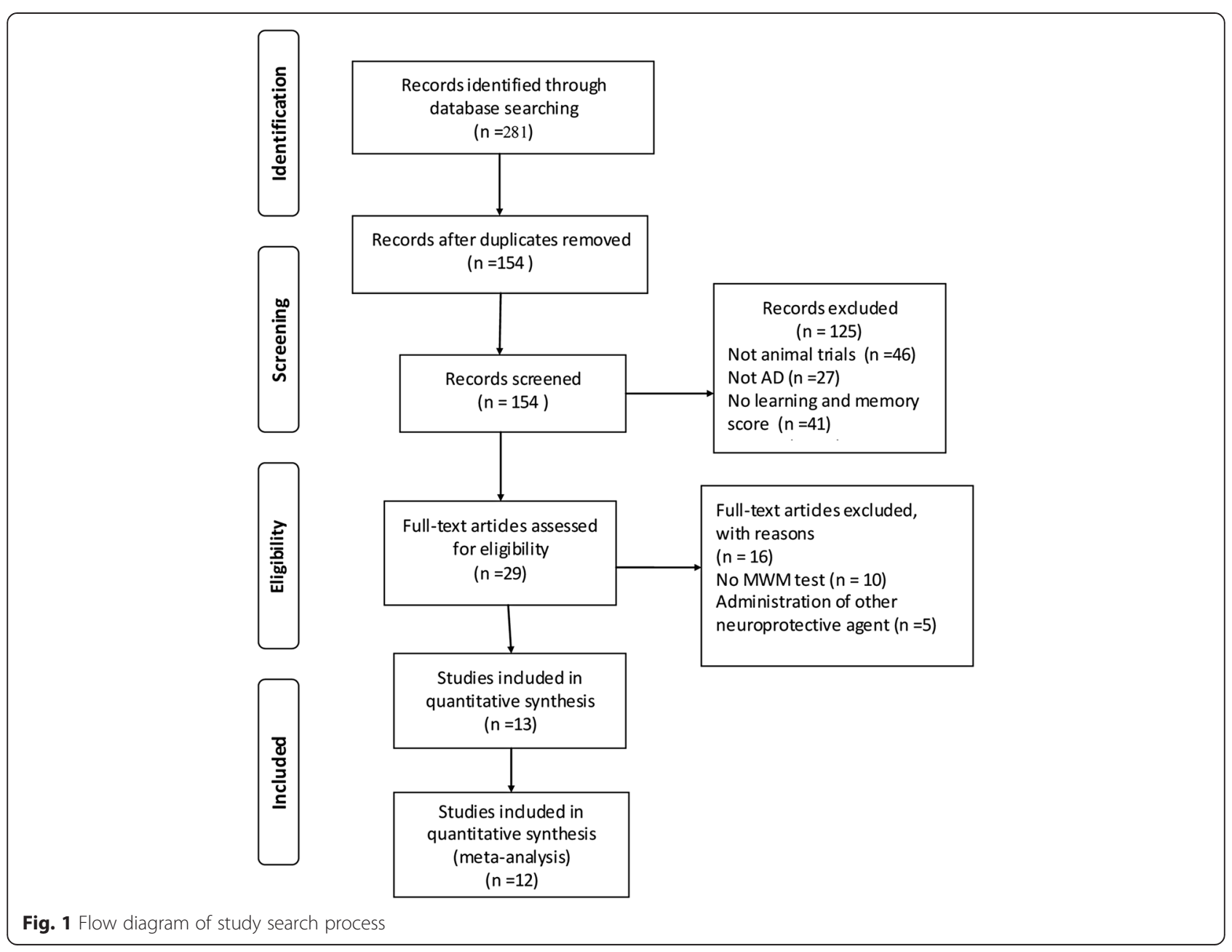


Table 4 Quality assessment of the included studies

\begin{tabular}{|c|c|c|c|c|c|c|c|c|c|c|c|c|}
\hline Study quality: & $\begin{array}{l}\text { Wang } \\
\text { YC }\end{array}$ & $\begin{array}{l}\text { Bombi } \\
\text { Lee }\end{array}$ & $\begin{array}{l}\text { Song } \\
X Y\end{array}$ & $\begin{array}{l}\text { Quan } \\
\text { QK }\end{array}$ & $\begin{array}{l}\text { Zhao } \\
\mathrm{HH}\end{array}$ & $\begin{array}{l}\text { Zhang } \\
X\end{array}$ & $\begin{array}{l}\text { Wang } \\
\text { YL }\end{array}$ & $\begin{array}{l}\text { Chu } \\
\text { SH }\end{array}$ & $\begin{array}{l}\text { Zhou } \\
\text { LP }\end{array}$ & $\begin{array}{l}\text { Wang } \\
\text { XY }\end{array}$ & $\begin{array}{l}\text { Wu } \\
\text { W }\end{array}$ & ZangY \\
\hline Research question specified and clear? & $\sqrt{ }$ & $\sqrt{ }$ & $\sqrt{ }$ & $\sqrt{ }$ & $\sqrt{ }$ & $\sqrt{ }$ & $\sqrt{ }$ & $\sqrt{ }$ & $\sqrt{ }$ & $\sqrt{ }$ & $\sqrt{ }$ & $\sqrt{ }$ \\
\hline Outcome measures relevant for $A D$ research & $\sqrt{ }$ & $\sqrt{ }$ & $\sqrt{ }$ & $\sqrt{ }$ & $\sqrt{ }$ & $\sqrt{ }$ & $\sqrt{ }$ & $\sqrt{ }$ & $\sqrt{ }$ & $\sqrt{ }$ & $\sqrt{ }$ & $\sqrt{ }$ \\
\hline \multicolumn{13}{|l|}{ Are the characteristics of study population clear? } \\
\hline Species & $\sqrt{ }$ & $\sqrt{ }$ & $\sqrt{ }$ & $\sqrt{ }$ & $\sqrt{ }$ & $\sqrt{ }$ & $\sqrt{ }$ & $\sqrt{ }$ & $\sqrt{ }$ & $\sqrt{ }$ & $\sqrt{ }$ & $\sqrt{ }$ \\
\hline Background/generation & $\sqrt{ }$ & $\sqrt{ }$ & $\sqrt{ }$ & $\sqrt{ }$ & $\sqrt{ }$ & $\sqrt{ }$ & $\sqrt{ }$ & $\sqrt{ }$ & $\sqrt{ }$ & $\sqrt{ }$ & $\sqrt{ }$ & $\sqrt{ }$ \\
\hline Sex (and distribution) & $\sqrt{ }$ & $\sqrt{ }$ & $\sqrt{ }$ & $\sqrt{ }$ & $\sqrt{ }$ & $\mathrm{N}$ & $\sqrt{ }$ & N & $\sqrt{ }$ & $\sqrt{ }$ & $\sqrt{ }$ & $N$ \\
\hline Age & $N$ & $\sqrt{ }$ & $\sqrt{ }$ & $\sqrt{ }$ & $\sqrt{ }$ & $\sqrt{ }$ & $\sqrt{ }$ & $\sqrt{ }$ & $\sqrt{ }$ & $\sqrt{ }$ & $\sqrt{ }$ & $\sqrt{ }$ \\
\hline Presence and correct control group? & $\sqrt{ }$ & $\sqrt{ }$ & $\sqrt{ }$ & $\sqrt{ }$ & $\sqrt{ }$ & $\sqrt{ }$ & $\sqrt{ }$ & $\sqrt{ }$ & $\sqrt{ }$ & $\sqrt{ }$ & $\sqrt{ }$ & $\sqrt{ }$ \\
\hline $\begin{array}{l}\text { Where the groups similar at baseline (if not } \\
\text { randomized think of weight and sex etc.)? }\end{array}$ & $\sqrt{ }$ & $\sqrt{ }$ & $\sqrt{ }$ & $\sqrt{ }$ & $\sqrt{ }$ & $N$ & $\sqrt{ }$ & N & $\sqrt{ }$ & $?$ & $\sqrt{ }$ & N \\
\hline Is the experiment randomized? & $\sqrt{ }$ & $\sqrt{ }$ & $\sqrt{ }$ & $\sqrt{ }$ & $\sqrt{ }$ & N & $\sqrt{ }$ & N & $\sqrt{ }$ & $\sqrt{ }$ & $\sqrt{ }$ & $\sqrt{ }$ \\
\hline Kind of supplement mentioned (ginsenoside)? & $\sqrt{ }$ & $\sqrt{ }$ & $\sqrt{ }$ & $\sqrt{ }$ & $\sqrt{ }$ & $\sqrt{ }$ & $\sqrt{ }$ & $\sqrt{ }$ & $\sqrt{ }$ & $\sqrt{ }$ & $\sqrt{ }$ & $\sqrt{ }$ \\
\hline Age when supplementation started mentioned? & $\sqrt{ }$ & $\sqrt{ }$ & $\sqrt{ }$ & $\sqrt{ }$ & $\sqrt{ }$ & $\sqrt{ }$ & $\sqrt{ }$ & $\sqrt{ }$ & $\sqrt{ }$ & $\sqrt{ }$ & $\sqrt{ }$ & $\sqrt{ }$ \\
\hline Duration of supplementation clear and specified? & $\sqrt{ }$ & $\sqrt{ }$ & $\sqrt{ }$ & $\sqrt{ }$ & $\sqrt{ }$ & $\sqrt{ }$ & $\sqrt{ }$ & $\sqrt{ }$ & $\sqrt{ }$ & $\sqrt{ }$ & $\sqrt{ }$ & $\sqrt{ }$ \\
\hline Amount of ginsenoside mentioned & $\sqrt{ }$ & $\sqrt{ }$ & $\sqrt{ }$ & $\sqrt{ }$ & $\sqrt{ }$ & $\sqrt{ }$ & $\sqrt{ }$ & $\sqrt{ }$ & $\sqrt{ }$ & $\sqrt{ }$ & $\sqrt{ }$ & $\sqrt{ }$ \\
\hline Administration route specified & $\sqrt{ }$ & $\sqrt{ }$ & $\sqrt{ }$ & $\sqrt{ }$ & $\sqrt{ }$ & $\sqrt{ }$ & $\sqrt{ }$ & $\sqrt{ }$ & $\sqrt{ }$ & $\sqrt{ }$ & $\sqrt{ }$ & $\sqrt{ }$ \\
\hline $\begin{array}{l}\text { Is the timing of the supplementation during the day } \\
\text { specified and similar in both groups? }\end{array}$ & $\sqrt{ }$ & $\sqrt{ }$ & $\sqrt{ }$ & $\sqrt{ }$ & $\sqrt{ }$ & $\sqrt{ }$ & $\sqrt{ }$ & $\sqrt{ }$ & $\sqrt{ }$ & $\sqrt{ }$ & $\sqrt{ }$ & $\sqrt{ }$ \\
\hline $\begin{array}{l}\text { Methods used for outcome assessment the same in } \\
\text { both groups? }\end{array}$ & $\sqrt{ }$ & $\sqrt{ }$ & $\sqrt{ }$ & $\sqrt{ }$ & $\sqrt{ }$ & $\sqrt{ }$ & $\sqrt{ }$ & $\sqrt{ }$ & $\sqrt{ }$ & $\sqrt{ }$ & $\sqrt{ }$ & $\sqrt{ }$ \\
\hline $\begin{array}{l}\text { Did report animals who died or were otherwise } \\
\text { removed from the study }\end{array}$ & N & N & N & N & N & N & N & N & N & N & N & N \\
\hline Blinded outcome assessment? & N & $\sqrt{ }$ & $N$ & N & N & $N$ & $\mathrm{~N}$ & N & N & N & N & N \\
\hline $\begin{array}{l}\text { Was the outcome assessment randomized across the } \\
\text { groups? }\end{array}$ & $N$ & $N$ & $N$ & N & N & $N$ & $N$ & N & $N$ & $N$ & N & $N$ \\
\hline $\begin{array}{l}\text { Total number of animals included in statistical } \\
\text { analyses clear? }\end{array}$ & $\sqrt{ }$ & $\sqrt{ }$ & $\sqrt{ }$ & $\sqrt{ }$ & $\sqrt{ }$ & $\sqrt{ }$ & $\sqrt{ }$ & $\sqrt{ }$ & $\sqrt{ }$ & $\sqrt{ }$ & $\sqrt{ }$ & $\sqrt{ }$ \\
\hline Age of sacrificing animals mentioned? & $\sqrt{ }$ & $\sqrt{ }$ & $\sqrt{ }$ & $\sqrt{ }$ & $\sqrt{ }$ & $\sqrt{ }$ & $\sqrt{ }$ & $\sqrt{ }$ & $\sqrt{ }$ & $\sqrt{ }$ & $\sqrt{ }$ & $\sqrt{ }$ \\
\hline Quality score (items $\sqrt{\text { ) }}$ & 17 & 19 & 18 & 18 & 18 & 15 & 18 & 15 & 18 & 17 & 18 & 18 \\
\hline
\end{tabular}

$\sqrt{ }=$ fulfilling the criterion, $n o=$ not fulfilling the criterion, $?=$ not enough information to determine whether or not the raised criterion is

female animals only [31, 33, 35]. One study [38] used equal numbers of male and female animals. Two studies [34, 37] did not report the sex of the animals used. Across all studies, ginsenoside Rg1, ginsenoside Rg2, ginsenoside Rg3, ginsenoside Rg5, and ginsenoside Rb1 were administered as experimental treatments in doses of $1,2,3,4,5,6,9,10,20$, or $30 \mathrm{mg} / \mathrm{kg} /$ day via either oral gavage or intraperitoneal injection. All studies used the MWM to assess cognitive function.

\section{Methodological quality of studies}

A large variety of tools to assess the quality of animal studies is currently used, but none of these tools focus on internal validity only. Most instruments assess the reporting quality and internal and external validity simultaneously even though the consequences associated with poor reporting, the risk of bias, or the generalizability of the results are different [39].
Therefore, two tools were used to assess the quality of each study using the CAMARADES checklist. Overall, the median quality score for the 12 included studies was poor (5.29; interquartile range: 5-6), with scores ranging from 4 to 8 . No study received a score of 0 or 10 . Three studies received scores that indicated high quality [27, 28,33 , and these 3 studies reported the monitoring of physiological parameters during surgical procedures. One study [34] did not report the randomization of animals into treatment groups. Three studies [31, 32, 35, 36] assessed dose-response relationships. Three studies $[30,31,33]$ stated no potential conflict of interests. Only one study [28] contained a statement that outcome measures were assessed by experimenters who were blind to the treatment condition. Moreover, no study described the sample size calculation to confirm that sufficient power had been achieved. The median quality score indicated that 17.5 out of 21 of the secondary 
criteria had been reported. The lowest score was 15 items (16.67\%) and the highest score was 19 items (8.33\%). Although treatment blinding and a description of the number of animals that died or were otherwise removed from the study are key measures for assessing the quality of studies, no study reported this information. One study [34] reported that investigators were blind to the treatment condition during the outcome assessment, and none of the papers described randomizing the order of the outcome assessments across the groups.

\section{Overall efficacy}

For acquisition memory, the global estimated effect of ginsenosides was -2.14 (95 \% CI: -2.69 to $-1.79, p<0.0001$ ) with significant heterogeneity among studies $\left(X^{2}=136.74\right.$, $\mathrm{df}=30, p<0.0001, I^{2}=83 \%$; Fig. $2 \mathrm{a}$ ). For retention memory, the global estimated effect of ginsenosides was 2.65 (95\% CI: 1.67 to $3.64, p<0.0001$ ), with significant heterogeneity among studies $\left(X^{2}=108.89, \mathrm{df}=12\right.$, $p<0.0001, I^{2}=89 \%$; Fig. 2b).

\section{Stratified meta-analysis}

Subgroup analyses were conducted to assess the degree to which methodological differences between trials might have systematically influenced the differences observed in the primary treatment outcomes. The overall summary of each subgroup then can be inspected for evidence of variation in the effects of the intervention, which would suggest that the stratifying characteristic is an important source of heterogeneity and may modify the treatment efficacy. Current guidelines recommend at least 10 studies per characteristic for stratifying subgroups [40]. The results of the stratified analyses are described in Table 5.

First, the protective effects of ginsenoside $\mathrm{Rb}$, ginsenoside Rg1, ginsenoside $\operatorname{Rg} 2$, ginsenoside $\operatorname{Rg} 3$, and ginsenoside $\operatorname{Rg} 5$ administration on cognitive performance were examined. $\operatorname{Rg} 1$ treatment had a significantly greater beneficial effect on acquisition memory and retention memory $\left(X^{2}=29.55, \mathrm{df}=4, p<0.00001, I^{2}=86.5 \%\right.$ and $X^{2}=6.15, \mathrm{df}=1, p=0.001, I^{2}=83.7 \%$, respectively) compared with $\mathrm{Rb}$ treatment, Rg2 treatment, Rg3 treatment, or Rg5 treatment. Next, the efficacy of different doses of ginsenosides on cognitive performance was analyzed. For both acquisition and retention memory, significant beneficial effects were noted for all doses of ginsenosides. The protective effects of $30 \mathrm{mg}$ or higher doses on acquisition memory were examined to determine whether the effects of higher doses are greater than those of lower doses. A $30 \mathrm{mg}$ or higher dose was associated with a greater beneficial effect than a dose less than $30 \mathrm{mg}$ on acquisition memory; however, no significant differences among doses were detected $\left(X^{2}=11.64, \mathrm{df}=3, p=0.009\right.$, $\left.I^{2}=74.2 \%\right)$. The protective effects at $10 \mathrm{mg}$ or higher doses on retention memory also were examined to determine whether the effects of higher doses are greater than lower doses, and a significant effect was found. A $10 \mathrm{mg}$ dose was associated with a significantly greater beneficial outcome compared with a dose less than $10 \mathrm{mg}$ or more than $10 \mathrm{mg}$ for retention memory $\left(X^{2}=12.16, \mathrm{df}=2\right.$, $p<0.002, I^{2}=83.5 \%$; Fig. 3$)$.

The protective effects of species and sex also were examined. For acquisition memory, although the effect size was higher in studies that used rat models, no significant difference was detected between studies that used rat models or mouse models $\left(X^{2}=6.97, \mathrm{df}=1, p=0.008\right.$, $\left.I^{2}=85.7 \%\right)$. However, for retention memory, the effect size was significantly higher in studies that used rat models compared with mouse models $\left(X^{2}=5.58, \mathrm{df}=1, p=0.002\right.$, $\left.I^{2}=82.1 \%\right)$. For both acquisition memory and retention memory, the effect size was significantly higher in studies that used female animals compared with male animals $\left(X^{2}=16.72, \mathrm{df}=3, p<0.0008, I^{2}=82.5 \%\right.$ and $X^{2}=$ $7.25, \mathrm{df}=1, p=0.003, I^{2}=72.4 \%$, respectively; Fig. 4).

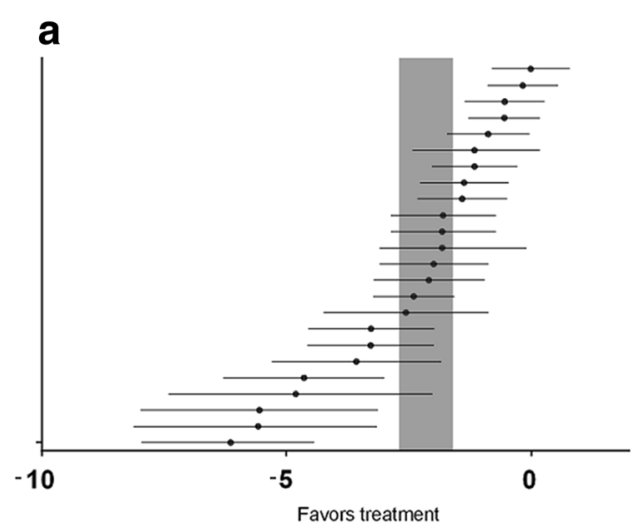

b

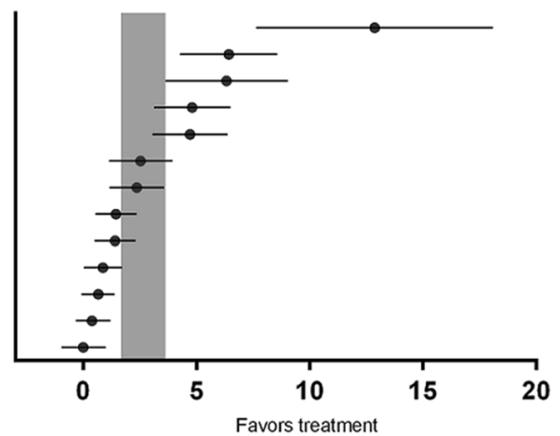

Fig. 2 The effects of ginsenosides on (a) acquisition memory and (b) retention memory. The horizontal lines represent the mean estimated effect size and the $95 \%$ confidence interval (Cl) for each comparison. The vertical gray bars represent the $95 \% \mathrm{Cl}$ of the pooled estimate effect size 
Table 5 The results of stratified meta-analysis

\begin{tabular}{|c|c|c|c|c|c|c|c|c|}
\hline \multirow[t]{2}{*}{ Subgroups } & \multicolumn{3}{|c|}{ Acquisition memory } & & \multicolumn{3}{|c|}{ Retention memory } & \\
\hline & Studies & Participants & Effect size, $95 \% \mathrm{Cl}$ & & Studies & Participants & Effect size , $95 \% \mathrm{Cl}$ & \\
\hline \multicolumn{9}{|l|}{ Gensenosides } \\
\hline $\mathrm{Rb}$ & 2 & 56 & $-2.21[-2.90,-1.53]$ & $P<0.00001$ & & & & \\
\hline $\mathrm{Rg} 1$ & 13 & 290 & $-2.86[-3.83,-1.90]$ & & 9 & 200 & $3.52[1.95,5.09]$ & $P=0.01$ \\
\hline $\operatorname{Rg} 2$ & 3 & 72 & $-1.31[-1.82,-0.79]$ & & 4 & 88 & $1.40[-0.84,1.97]$ & \\
\hline $\mathrm{Rg} 3$ & 3 & 36 & $-2.56[-4.42,-0.71]$ & & & & & \\
\hline $\operatorname{Rg} 5$ & 3 & 72 & $-0.46[-0.96,0.04]$ & & & & & \\
\hline \multicolumn{9}{|l|}{ Dose } \\
\hline $1-9 \mathrm{mg}$ & 9 & 216 & $-1.287[-1.92,-0.62]$ & $P=0.009$ & 7 & 172 & $1.17[0.42,1.93]$ & $P=0.002$ \\
\hline $10 \mathrm{mg}$ & 9 & 206 & $-2.54[-3.49,-1.59]$ & & 3 & 60 & $6.54[1.97,11.1]$ & \\
\hline $20 \mathrm{mg}$ & 5 & 92 & $-2.90[-4.51,-1.28]$ & & 3 & 56 & $4.30[2.22,6.37]$ & \\
\hline $30 \mathrm{mg}$ & 1 & 12 & $-4.81[-7.41,2.20]$ & & & & & \\
\hline \multicolumn{9}{|l|}{ Animal species } \\
\hline Mouse & 6 & 136 & $-1.21[-1.87,-0.55]$ & $P=0.008$ & 4 & 96 & $1.35[0.34,2.35]$ & $P=0.002$ \\
\hline Rat & 18 & 390 & $-2.52[-3.24,-1.80]$ & & 9 & 192 & $3.52[2.02,5.01]$ & \\
\hline \multicolumn{9}{|l|}{ Gender } \\
\hline Male & 11 & 258 & $-2.65[-3.66,-1.63]$ & $P=0.0008$ & 5 & 256 & $3.22[1.66,6.26]$ & $P=0.003$ \\
\hline Female & 5 & 84 & $-3.42[-4.84,-2.00]$ & & 5 & 84 & $3.78[1.38,6.10]$ & \\
\hline Mixed & 3 & 72 & $-1.31[-1.82,-0.79]$ & & 3 & 73 & $1.22[0.70,1.73]$ & \\
\hline Unclear & 5 & 112 & $-0.86[-1.46,-0.26]$ & & & & & \\
\hline \multicolumn{9}{|l|}{ Anesthetic agent } \\
\hline Pentobarbital & 4 & 52 & $-2.22[-3.40,-1.05]$ & $P=0.06$ & 1 & 16 & $2.53[1.13,3.94]$ & $P=0.87$ \\
\hline Chloral hydrate & 14 & 322 & $-2.66[-3.52,-1.80]$ & & 12 & 272 & $2.68[1.63,3.72]$ & \\
\hline Ether & 2 & 40 & $-1.58[-2.32,-0.85]$ & & & & & \\
\hline Unclear & 4 & 112 & $-0.95[-1.96,0.06]$ & & & & & \\
\hline \multicolumn{9}{|l|}{ Drug delivery } \\
\hline ip & 17 & 366 & $-2.23[-2.87,-1.58]$ & $P=0.68$ & 9 & 200 & $1.61[0.73,2.49]$ & $P=0.002$ \\
\hline Or & 7 & 160 & $-1.95[-3.09,-0.81]$ & & 4 & 88 & $4.50[2.92,6.08]$ & \\
\hline \multicolumn{9}{|l|}{ Study quality } \\
\hline 4 & 2 & 50 & $-4.05[-8.02,-0.08]$ & $P<0.00001$ & 1 & 20 & $2.36[1.16,3.56]$ & $P<0.001$ \\
\hline 5 & 3 & 72 & $-1.31[-1.82,-0.79]$ & & 6 & 132 & $1.22[2.92,6.08]$ & \\
\hline 6 & 11 & 260 & $-1.90[-2.63,-1.17]$ & & 4 & 88 & $4.50[2.92,6.08]$ & \\
\hline 7 & 2 & 60 & $-0.36[-0.87,0.15]$ & & 6 & 124 & $0.52[0.00,1.03]$ & \\
\hline 8 & 6 & 84 & $-3.66[-5.20,-2.13]$ & & 3 & 48 & $5.98[-0.63,12.59]$ & \\
\hline
\end{tabular}

The effect of the anesthetic agent and the route of drug delivery also were examined. For acquisition memory and retention memory, although the effect size was higher in studies that used chloral hydrate anesthesia, no significant differences among anesthetic agents were detected $\left(X^{2}=7.38, \mathrm{df}=3, p=0.006, I^{2}=53.6 \%\right.$ and $X^{2}=0.03$, $\mathrm{df}=1, p=0.87, I^{2}=0 \%$, respectively; Fig. 5). For acquisition memory, although the effect size was higher in studies that used intraperitoneal injection, no significant differences in the routes of drug delivery were detected $\left(X^{2}=0.17, \mathrm{df}=1, p=0.68, I^{2}=0 \%\right.$; Fig. $\left.5 \mathrm{c}\right)$. Oral gavage was associated with a significantly greater beneficial outcome than intraperitoneal injection for retention memory $\left(X^{2}=9.83, \mathrm{df}=1, p=0.002\right.$, and $I^{2}=89.8 \%$; Fig. $\left.5 \mathrm{~d}\right)$.

The effect sizes for acquisition and retention memory also were examined relative to the study quality score. Significant differences in effect sizes were observed between lower-scoring and higher-scoring studies for both acquisition $\left(X^{2}=25.03, \mathrm{df}=4, p<0.00001, I^{2}=84.3 \%\right)$ and retention $\left(X^{2}=29.03, \mathrm{df}=4, p<0.00001, I^{2}=86.2 \%\right)$ memory. The effect size for acquisition memory was maximal for studies with a quality score of $4 \cdot(-4.05$, 

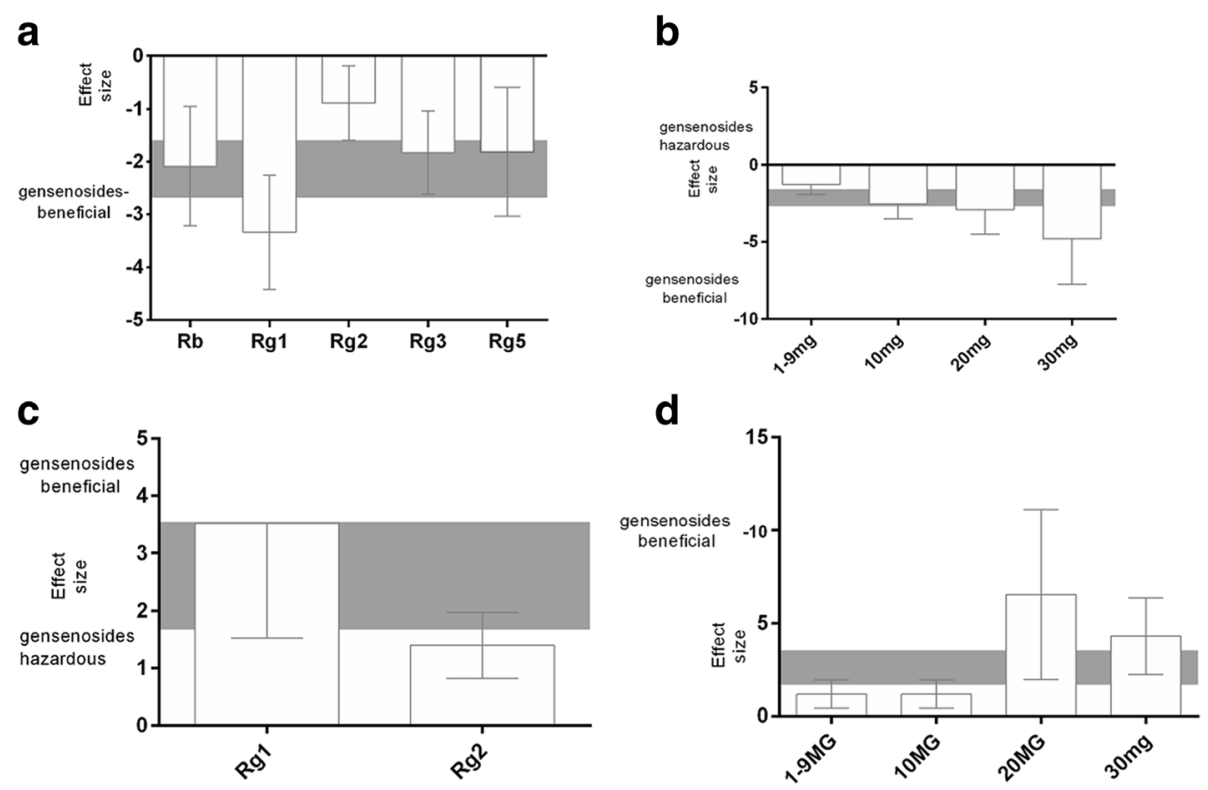

Fig. 3 The effect size for acquisition memory is stratified by (a) the type of Ginsenosides; and (b) the dose. The effect size for retention memory is stratified by (c) the type of Ginsenosides; and (d) the dose. The gray bands represent the $95 \% \mathrm{Cl}$ for the global estimated effect size
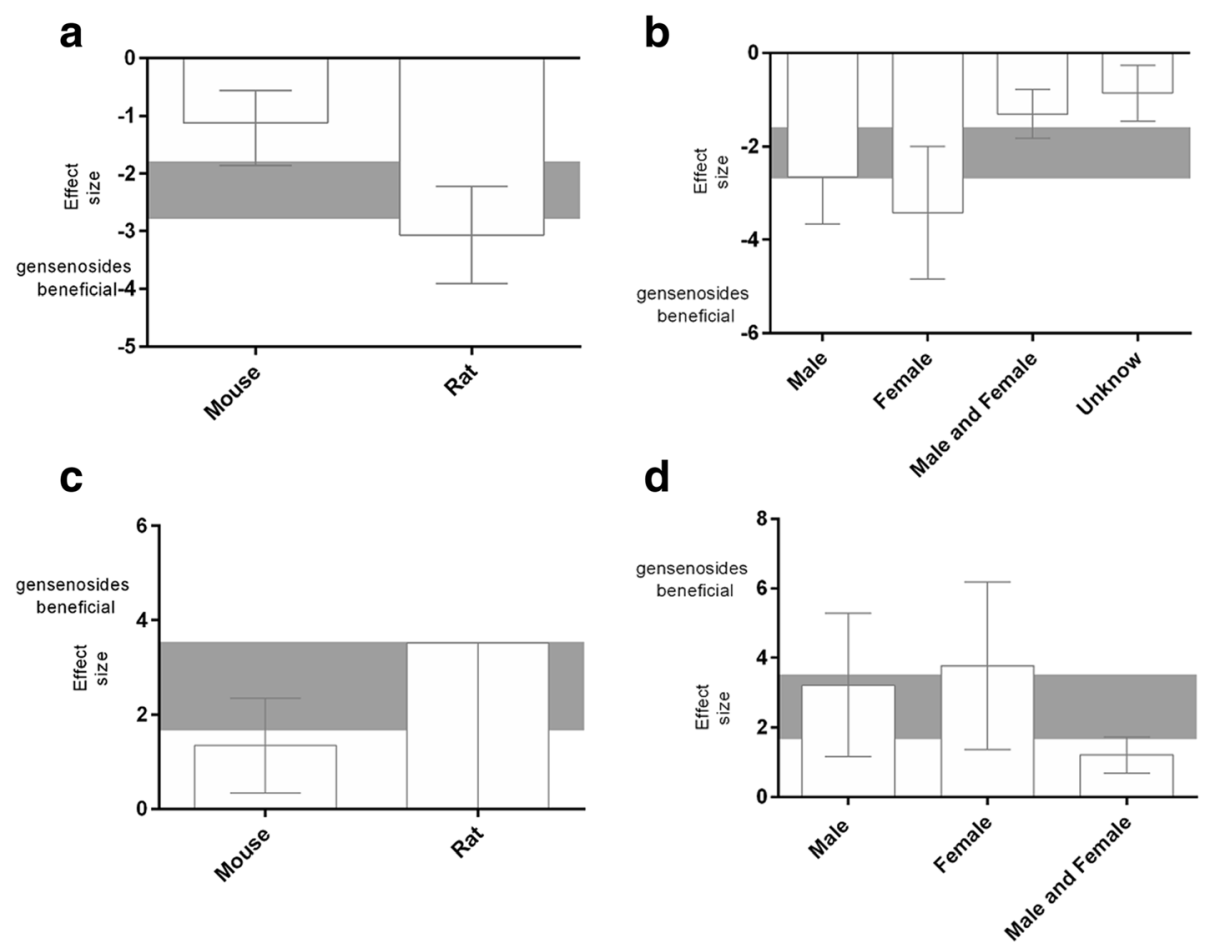

Fig. 4 The effect size for acquisition memory is stratified by (a) species; and (b) sex. The effect size for retention memory is stratified by (c) species; and (d) sex. The gray bands represent the $95 \% \mathrm{Cl}$ for the global estimated effect size 


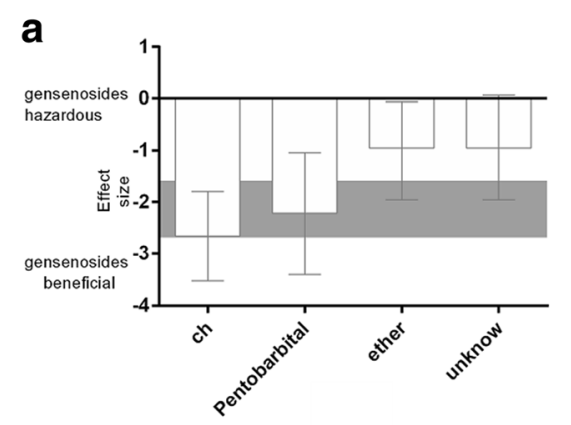

C

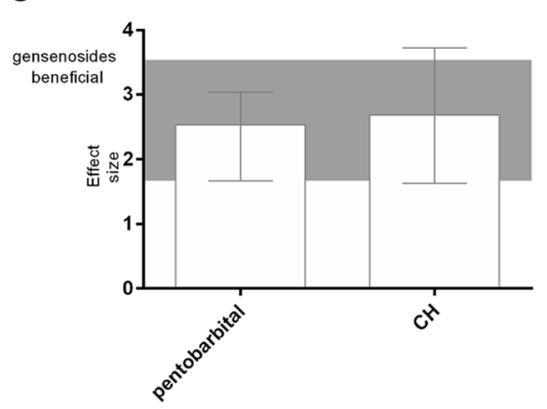

b

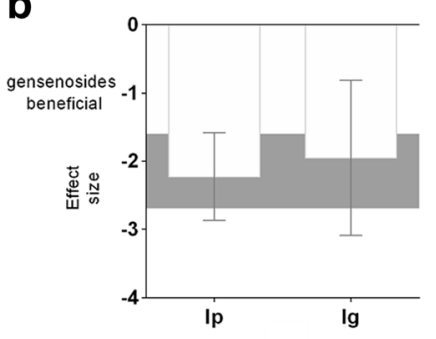

d

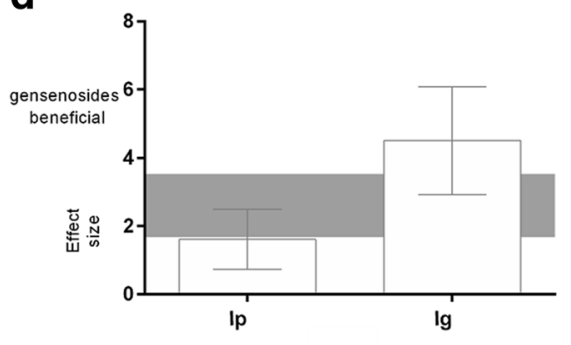

Fig. 5 The effect size for acquisition memory is stratified by (a) anesthetic agent; and (b) route of delivery. The effect size for retention memory is stratified by (c) anesthetic agent; and (d) route of delivery. The gray bands represent the $95 \% \mathrm{Cl}$ for the global estimated effect size

$95 \%$ CI: -8.02 to -0.08 ; Fig. 6a), and the effect size for retention memory was higher for studies with a quality score of 8 (5.98, $95 \%$ CI: -0.63 to 12.59 ; Fig. $6 \mathrm{~b})$ than those with lower scores.

\section{Meta-regression analyses}

Meta-regression is an extension of the subgroup analysis that allows for the investigation of the effect of multiple factors simultaneously. The outcome variable is the effect estimate, and the explanatory variables are the study characteristics that might influence the effect size, which are often called the "potential effect modifiers" or covariates.

To further explore the heterogeneity among studies, meta-regression was conducted for the acquisition and retention memory results. For retention memory, the species and sex of the animals, anesthetic method, type and dose of ginsenoside, study quality score, and route of drug delivery explained $49.03 \%$ of the heterogeneity. For acquisition memory, heterogeneity was independent of these factors.

\section{Publication bias}

Finally, the presence of small-study effects, which may contribute to publication bias, were identified. Funnel plots showed an asymmetry for both the acquisition (Fig. 7a) and retention memory (Fig. 7b) data, which provides evidence for small-study effects (Egger regression, $p<0.0001$ and $p<0.001$, respectively).
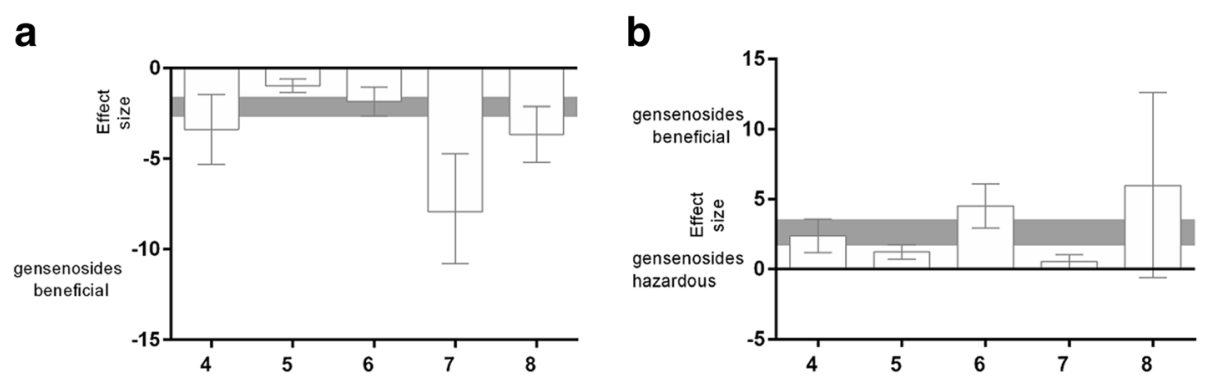

Fig. 6 The effect size is stratified by study quality score (a) for acquisition memory and (b) for retention memory. The gray bands represent the $95 \% \mathrm{Cl}$ for the global estimated effect size. The gray bands represent the $95 \%$ Cl for the global estimated effect size 

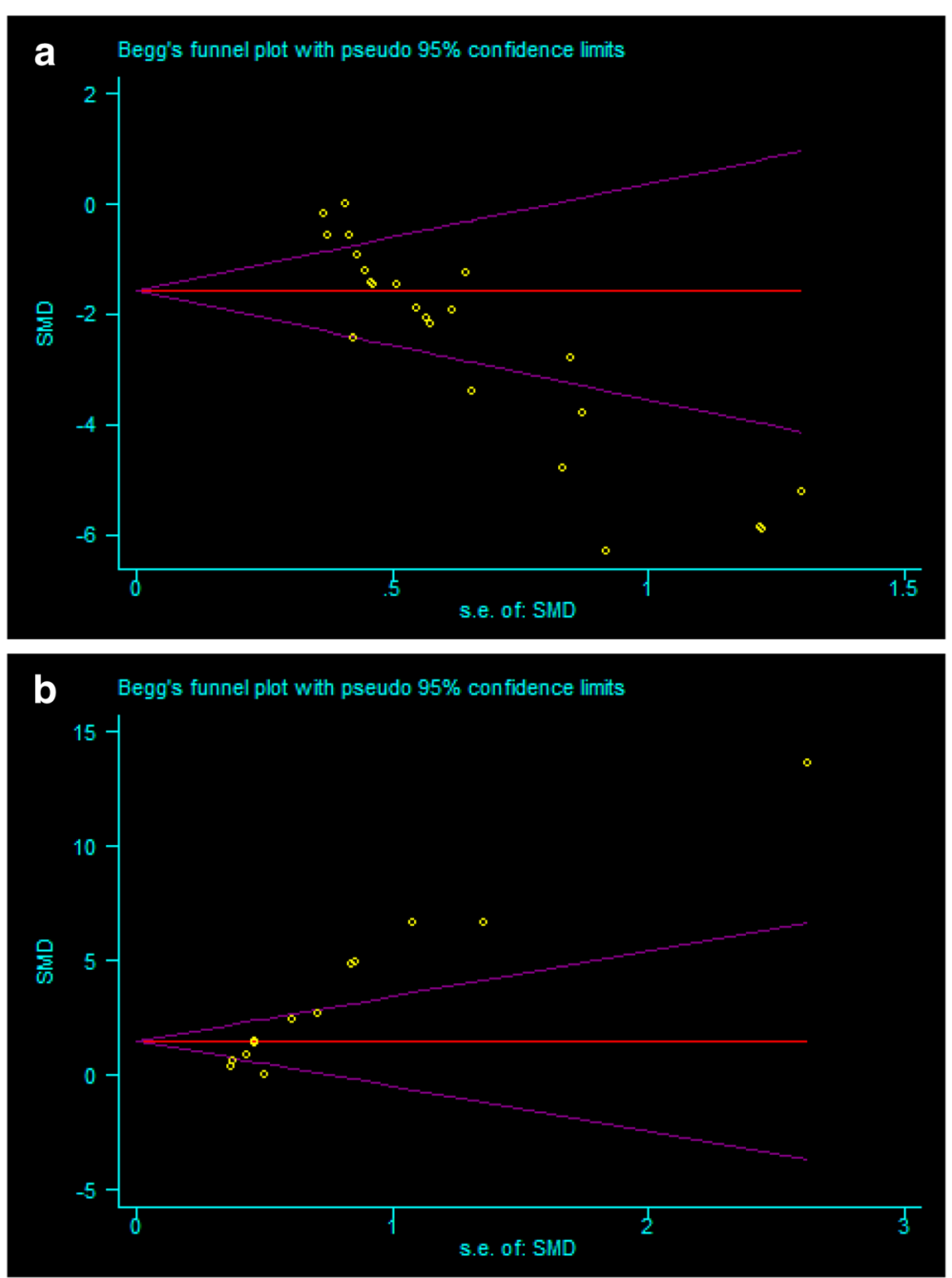

Fig. 7 Funnel plot for acquisition memory (a) and retention memory (b)

\section{Possible drug protection mechanism analysis}

All studies that were included in the analysis assessed the biological mechanisms of ginsenoside activity. Across studies, the neuroprotective effect of ginsenoside was attributed primarily to anti-inflammatory activity [28, 32, 34]. Ginsenoside was reported to promote the non-amyloidgenic cleavage of beta-amyloid precursor protein (APP) [18], attenuate $A \beta$ formation [29], decrease $A \beta$ levels, attenuate hippocampal histopathological abnormalities [30], prevent tau hyperphosphorylation via the regulation of p-GSK3 and serine/threonine-specific protein phosphatase $2 \mathrm{~A}$ levels [31], activate the endoplasmic reticulum signaling pathway, inhibit the activity of acetylcholinesterase [37], and upregulate the expression of nerve growth factor [36].

\section{Discussion}

Many animal experiments are performed to inform human health, and may play an important role in the identification and development of drugs, medical devices, and surgical procedures; risk assessments for safe human exposures; and increasing biological knowledge. It would seem rational to critically review the existing relevant animal experiments before new animal experiments and, in particular, clinical trials in humans are performed. Systematic reviews and meta-analyses are suitable tools to summarize the current evidence on a given subject, and therefore directly support the 'three Rs' (i.e., replacement, reduction, and refinement) by, for example, preventing the unnecessary duplication of animal studies. Systematic reviews and meta-analyses play an important role in physics, the social sciences, and medicine [41].

The results of this systematic review and meta-analysis show that ginsenoside provides neuroprotective effects in terms of improving cognitive outcomes in AD. Ginsenoside Rg1 exhibited the highest protective effect on both acquisition and retention memory. The species and sex of the animals, the type and dose of ginsenoside, and the study quality all had significant impacts on the effect 
size. In contrast, the route of drug delivery and the anesthetic method had no significant effects on the outcomes. Our analysis also suggests that some aspects of the original study design had an impact on the study outcome. First, the effect size was higher in rat studies than in mouse studies, which suggests that different species may react differently to ginsenoside. Second, the route of administration and dosage of ginsenoside also affected the outcome [42]. The protective effect on acquisition memory was better with doses of $30 \mathrm{mg}$ or higher (although not significantly) and the protective effect on retention memory was better with doses of $10 \mathrm{mg}$. These results are not consistent with the doselinear response curve described previously, in which higher doses yielded a greater response [43]. The effect size probably was overstated in studies that administered lower doses.

The methodological quality of the studies was assessed according to standards previously described for the preclinical development of neuroprotective drugs with minor modifications [22, 24]. In general, the quality of the included studies was poor. For example, only one study reported that investigators were blind to the treatment condition during the behavioral assessments. Treatment blinding is recommended in open-label trials to reduce bias. If patients, clinicians, or assessors are aware of the treatment assignment, then this knowledge may influence the reporting or measurement of the outcome and introduce bias [44]. Moreover, all the studies failed to report the calculation of the sample size necessary to achieve sufficient power, which is crucial to judge the efficacy of a new therapy or drug [45]. Unfortunately, the reporting of sample size elements specific to these random trials remains below that necessary for transparent reporting. The authors should calculate the sample size during the planning phase of the study to assess the accuracy of the a priori estimates and aid the design of future trials. In addition, journal editors and peer reviewers should implement stricter requirements for authors to follow CONSORT recommendations [46]. All studies failed to report animals that died or were otherwise removed from the study. As these events may have been due to medication side effects, this information is important in assessing the use of ginsenoside.

Systematic reviews can use research data from numerous study designs. However, when conducting systematic reviews of interventions, studies conducted using low evidentiary designs for evaluating real-world efficacy are generally not appropriate for inclusion [47]. In our systematic review, high quality studies showed a trend toward better acquisition memory outcomes, but studies with lower quality scores exhibited the highest protective effect on retention memory. The effect size was probably overstated in studies with lower quality scores.
Our study has several limitations. First, although we conducted a thorough literature search, we did not conduct a search of older data that has not been indexed in an electronic/online database. Our analysis is based only on published data or academic dissertation data available online, most of which showed positive results; therefore, our study may have missed 'negative' results. In addition, positive results, which are easier to publish, often appear in journals with higher impact factors than negative results [48]. The funnel plots and Egger tests suggest the possibility of a publication bias or other small-study bias, which is consistent with observations from other systematic reviews of animal studies [49]. Publication bias, which is considered a potential threat to the validity of all systematic reviews that include experimental studies, may have led to an overestimation of the protective effect of ginsenoside in our study. Second, we focused only on the effect of ginsenoside on cognitive deficits in AD. We did not conduct analyses to investigate the effect on histopathology, such as plaques and tangles, due to insufficient data. Third, due to language barriers, we only searched databases for articles published in English or Chinese, and did not search for studies published in other languages such as Korean. Korea is one of the main countries that uses ginseng, and therefore we may have missed some relevant publications. In addition, the animals used in the included studies were young rodents, which is not consistent with the average age of humans in the relevant clinical setting of AD. There remain some unknown factors that contributed to the heterogeneity of the effect size in our study. The number of preclinical experiments performed each year continues to increase, and our understanding of the disease mechanism is improving. However, the number of novel interventions that reach the clinic to treat cerebrovascular diseases continues to fall due to limitations in the translational paradigm [50]. The standardization of animal protocols and the systematic review of animal models that do not currently qualify as predictive modalities for human responses to drugs and disease are supported by experts in various fields of science [51]. Therefore, these limited results may not be adequate for the transition from animal experiments to human clinical trials. Consequently, prior to making any clinical practice recommendations, high methodological reporting and quality control experimental studies are needed to better evaluate the impact of this promising pharmacological intervention for $\mathrm{AD}$.

\section{Conclusion}

This systematic review and meta-analysis indicates that treatment with ginsenoside can alleviate cognitive deficits in experimental animal models of AD. Although some factors, such as the study quality and a potential publication 
bias, may undermine the validity of these positive findings, ginsenosides may play a potential neuroprotective role in $\mathrm{AD}$. However, without rigorous, robust, and detailed preclinical evaluations, novel neuroprotective drugs may prove to be ineffective when tested in large, time-consuming, and expensive human clinical trials. Therefore, additional welldesigned and well-reported experimental animal studies are needed.

\section{Competing interest}

The authors declare that they have no competing interests.

\section{Authors' contributions}

All authors have contributed to this article. CS and WP searched the databases, extracted the data, screened trials and appraised the quality of included trials. CS and ZX, reformed the tables and drafted the full text. YW ZC and NS were responsible for editing. ZW acted as an arbitrator and conceived the article. All authors reviewed the manuscript. All authors read and approved the final manuscript.

\section{Acknowledgements}

This research was supported by the Natural Science Foundation of the Hunan Province of China (No. 13JJ3030), the National Science Foundation of China (No. 81373705) and the Hunan Province Administration of Traditional Chinese Medicine (No. 201346).

\section{Author details}

${ }^{1}$ Department of Integrated Chinese and Western Medicine, The Second Xiangya Hospital, Central South University, No.139 Middle Renmin Road, Changsha, Hunan 410011, PR China. ${ }^{2}$ Institute of Integrative Medicine, Xiangya Hospital, Central South University, Changsha 410008Hunan, PR China. ${ }^{3}$ Key Laboratory of Chinese Gan of State Administration of Traditional Chinese Medicine of China, Changsha 410008Hunan, PR China.

\section{Received: 22 July 2015 Accepted: 4 October 2015}

\section{Published online: 24 October 2015}

\section{References}

1. Vinters HV. Emerging Concepts in Alzheimer's Disease. Annu Rev Pathol. 2014;10:291-319.

2. Bolognin S, Blanchard J, Wang X, Basurto-Islas G, Tung YC, Kohlbrenner E, et al. An experimental rat model of sporadic Alzheimer's disease and rescue of cognitive impairment with a neurotrophic peptide. Acta Neuropathol. 2012;123(1):133-51.

3. Passoni S, Mazza M, Zanardi G, Bottini G. Levels of burden of Alzheimer disease caregivers. G Ital Med Lav Ergon. 2010;32(3 Suppl B):B37-42.

4. Wang $X$, Kim JR, Lee SB, Kim YJ, Jung MY, Kwon HW, et al. Effects of curcuminoids identified in rhizomes of Curcuma longa on BACE-1 inhibitory and behavioral activity and lifespan of Alzheimer's disease Drosophila models. BMC Complement Altern Med. 2014;14:88.

5. Lu Y, Huang Y, Tang C, Shan B, Cui S, Yang J, et al. Brain areas involved in the acupuncture treatment of AD model rats: a PET study. BMC Complement Altern Med. 2014;14:178.

6. Wu CR, Lin HC, Su MH. Reversal by aqueous extracts of Cistanche tubulosa from behavioral deficits in Alzheimer's disease-like rat model: relevance for amyloid deposition and central neurotransmitter function. BMC Complement Altern Med. 2014;14:202.

7. Jeong $\mathrm{JH}$, Jeong HR, Jo YN, Kim HJ, Shin JH, Heo HJ. Ameliorating effects of aged garlic extracts against Abeta-induced neurotoxicity and cognitive impairment. BMC Complement Altern Med. 2013;13:268.

8. Liu Z, Li T, Li P, Wei N, Zhao Z, Liang H, et al. The Ambiguous Relationship of Oxidative Stress, Tau Hyperphosphorylation, and Autophagy Dysfunction in Alzheimer's Disease. Oxidative Med Cell Longev. 2015;2015:352723.

9. labal K, Gong CX, Liu F. Microtubule-associated protein tau as a therapeutic target in Alzheimer's disease. Expert Opin Ther Targets. 2014;18(3):307-18.

10. Hu BY, Liu XJ, Qiang R, Jiang ZL, Xu LH, Wang GH, et al. Treatment with ginseng total saponins improves the neurorestoration of rat after traumatic brain injury. J Ethnopharmacol. 2014;155(2):1243-55.
11. Wang L, Kisaalita WS. Administration of BDNF/ginsenosides combination enhanced synaptic development in human neural stem cells. J Neurosci Methods. 2011;194(2):274-82.

12. Huang C, Qian ZG, Zhong JJ. Enhancement of ginsenoside biosynthesis in cell cultures of Panax ginseng by $N$, N'-dicyclohexylcarbodiimide elicitation. J Biotechnol. 2013;165(1):30-6.

13. Heo JH, Lee ST, Chu K, Oh MJ, Park HJ, Shim JY, et al. Heat-processed ginseng enhances the cognitive function in patients with moderately severe Alzheimer's disease. Nutr Neurosci. 2012;15((6)):278-82.

14. Shi YQ, Huang TW, Chen LM, Pan XD, Zhang J, Zhu YG, et al. Ginsenoside Rg attenuates amyloid-beta content, regulates PKAVCREB activity, and improves cognitive performance in SAMP8 mice. J Alzheimers Dis. 2010;19(3):977-89.

15. He Y, Zhao H, Su G. Ginsenoside Rg1 decreases neurofibrillary tangles accumulation in retina by regulating activities of neprilysin and PKA in retinal cells of AD mice model. J Mol Neurosci. 2014;52(1):101-6.

16. Shi C, Zheng DD, Fang L, Wu F, Kwong WH, Xu J. Ginsenoside Rg1 promotes nonamyloidgenic cleavage of APP via estrogen receptor signaling to MAPKJERK and PI3K/Akt. Biochim Biophys Acta. 2012;1820(4):453-60.

17. Zhao R, Zhang Z, Song Y, Wang D, Qi J, Wen S. Implication of phosphatidylinositol-3 kinase/Akt/glycogen synthase kinase-3beta pathway in ginsenoside Rb1's attenuation of beta-amyloid-induced neurotoxicity and tau phosphorylation. J Ethnopharmacol. 2011;133(3):1109-16.

18. Qiu J, Li W, Feng SH, Wang M, He ZY. Ginsenoside Rh2 promotes nonamyloidgenic cleavage of amyloid precursor protein via a cholesteroldependent pathway. Genet Mol Res. 2014;13(2):3586-98.

19. Liu J, Yan X, Li L, Zhu Y, Qin K, Zhou L, et al. Ginsennoside rd attenuates cognitive dysfunction in a rat model of Alzheimer's disease. Neurochem Res. 2012;37(12):2738-47

20. van Luijk J, Leenaars M, Hooijmans C, Wever K, de Vries R, Ritskes-Hoitinga M. Towards evidence-based translational research: the pros and cons of conducting systematic reviews of animal studies. Altex. 2013;30(2):256-7.

21. Peng $W$, Yang J, Yang $B$, Wang $L$, Xiong XG, Liang Q. Impact of statins on cognitive deficits in adult male rodents after traumatic brain injury: a systematic review. Biomed Res Int. 2014;2014:261409.

22. Macleod MR, O'Collins T, Howells DW, Donnan GA. Pooling of animal experimental data reveals influence of study design and publication bias. Stroke. 2004;35(5):1203-8.

23. Crossley NA, Sena E, Goehler J, Horn J, van der Worp B, Bath PM, et al. Empirical evidence of bias in the design of experimental stroke studies: a metaepidemiologic approach. Stroke. 2008;39(3):929-34.

24. Hooijmans CR, Pasker-de Jong PC, de Vries RB, Ritskes-Hoitinga M. The effects of long-term omega-3 fatty acid supplementation on cognition and Alzheimer's pathology in animal models of Alzheimer's disease: a systematic review and meta-analysis. J Alzheimers Dis. 2012;28(1):191-209.

25. Zhang HW, Lin ZX, Xu C, Leung C, Chan LS. Astragalus (a traditional Chinese medicine) for treating chronic kidney disease. Cochrane Database Syst Rev. 2014;10:CD008369.

26. Lesack K, Naugler C. An open-source software program for performing Bonferroni and related corrections for multiple comparisons. J Pathol Inform. 2011;2:52.

27. Wang $Y$, Kan H, Yin Y, Wu W, Hu W, Wang M, et al. Protective effects of ginsenoside Rg1 on chronic restraint stress induced learning and memory impairments in male mice. Pharmacol Biochem Behav. 2014;120:73-81.

28. Lee B, Sur B, Park J, Kim SH, Kwon S, Yeom M, et al. Ginsenoside rg3 alleviates lipopolysaccharide-induced learning and memory impairments by anti-inflammatory activity in rats. Biomol Ther. 2013;21(5):381-90.

29. Song XY, Hu JF, Chu SF, Zhang Z, Xu S, Yuan YH, et al. Ginsenoside Rg1 attenuates okadaic acid induced spatial memory impairment by the GSK3beta/tau signaling pathway and the Abeta formation prevention in rats. Eur J Pharmacol. 2013;710(1-3):29-38.

30. Quan Q, Wang J, Li X, Wang Y. Ginsenoside Rg1 decreases Abeta(1-42) level by upregulating PPARgamma and IDE expression in the hippocampus of a rat model of Alzheimer's disease. PLoS ONE. 2013;8(3):e59155.

31. Zhao HH, Di J, Liu WS, Liu HL, Lai H, Lu YL. Involvement of GSK3 and PP2A in ginsenoside Rb1's attenuation of aluminum-induced tau hyperphosphorylation. Behav Brain Res. 2013;241:228-34.

32. Wang Y, Liu J, Zhang Z, Bi P, Qi Z, Zhang C. Anti-neuroinflammation effect of ginsenoside $\mathrm{Rbl}$ in a rat model of Alzheimer disease. Neurosci Lett. 2011;487(1):70-2.

33. Zhang X, Wang J, Xing Y, Gong L, Li H, Wu Z, et al. Effects of ginsenoside Rg1 or $17 \beta$-estradiol on a cognitively impaired, ovariectomized rat model of Alzheimer's disease. Neuroscience. 2012;220:191-200. 
34. Chu S, Gu J, Feng L, Liu J, Zhang M, Jia X, et al. Ginsenoside Rg5 improves cognitive dysfunction and beta-amyloid deposition in STZ-induced memory impaired rats via attenuating neuroinflammatory responses. Int Immunopharmacol. 2014;19(2):317-26.

35. Zhou L, Ge K, Chen W. Protection of ginsenoside Rg1 on amyloid beta (25-35)- induced neurotoxicity in mice hippocampal neurons. Acta Academiae Medicinae Qingdao Univ. 2011:47(3):189-91.

36. Wu W, Yang JQ, He ZY. Effect of ginsenoside Rg1 on the spatial learning-memory ability in dementia rats after transplanted with bone marrow mesenchymal stem cells. Zhongguo Zhong Xi Yi Jie He Za Zhi. 2011;31(6):799-802.

37. Wang XY, Chen J, Zhang JT. Effect of ginsenoside Rg1 on learning and memory impairment induced by beta-amyloid peptide(25-35) and its mechanism of action. Yao Xue Xue Bao. 2001;36(1):1-4.

38. Zang Y, Shi B, Cui L. Effect of ginsenoside Rg2 on on the spatial learningmemory ability and senile plaque formation in Alzheimer's disease rat. Chin J Gerontol. 2011;30(3):201-4.

39. Hooijmans CR, Rovers MM, de Vries RB, Leenaars M, Ritskes-Hoitinga $M_{t}$ Langendam MW. SYRCLE's risk of bias tool for animal studies. BMC Med Res Methodol. 2014;14:43.

40. Amos T, Stein DJ, Ipser JC. Pharmacological interventions for preventing posttraumatic stress disorder (PTSD). Cochrane Database Syst Rev. 2014;7:CD006239.

41. Korevaar DA, Hooft L, ter Riet G. Systematic reviews and meta-analyses of preclinical studies: publication bias in laboratory animal experiments. Lab Anim. 2011:45(4):225-30.

42. Devreese M, Antonissen G, De Baere S, De Backer P, Croubels S. Effect of administration route and dose escalation on plasma and intestinal concentrations of enrofloxacin and ciprofloxacin in broiler chickens. BMC Vet Res. 2014;10(1):289

43. Dubois B, Zaim M, Touchon J, Vellas B, Robert P, Murphy MF, et al. Effect of six months of treatment with V0191 in patients with suspected prodromal Alzheimer's disease. J Alzheimers Dis. 2012;29(3):527-35.

44. Kahan BC, Cro S, Dore CJ, Bratton DJ, Rehal S, Maskell NA, et al. Reducing bias in open-label trials where blinded outcome assessment is not feasible: strategies from two randomised trials. Trials. 2014;15:456.

45. Held U. On the impact of sample size calculation and power in clinical research. Praxis. 2014;103(20):1197-201.

46. Rutterford C, Taljaard M, Dixon S, Copas A, Eldridge S. Reporting and methodological quality of sample size calculations in cluster randomized trials could be improved: a review. J Clin Epidemiol. 2014;68((6)):716-23.

47. Sargeant JM, Kelton DF, O'Connor AM. Study designs and systematic reviews of interventions: building evidence across study designs. Zoonoses Public Health. 2014;61 Suppl 1:10-7.

48. Mimouni M, Krauthammer M, Gershoni A, Mimouni F, Nesher R. Positive Results Bias and Impact Factor in Ophthalmology. Curr Eye Res. 2014;40((8)):858-61.

49. Peng W, Xing Z, Yang J, Wang Y, Wang W, Huang W. The efficacy of erythropoietin in treating experimental traumatic brain injury: a systematic review of controlled trials in animal models. J Neurosurg. 2014;121(3):653-64.

50. Sena ES, Currie GL, McCann SK, Macleod MR, Howells DW. Systematic reviews and meta-analysis of preclinical studies: why perform them and how to appraise them critically. J Cereb Blood Flow Metab. 2014;34(5):737-42.

51. Greek R, Menache A. Systematic reviews of animal models: methodology versus epistemology. Int J Med Sci. 2013;10(3):206-21.

\section{Submit your next manuscript to BioMed Central and take full advantage of:}

- Convenient online submission

- Thorough peer review

- No space constraints or color figure charges

- Immediate publication on acceptance

- Inclusion in PubMed, CAS, Scopus and Google Scholar

- Research which is freely available for redistribution 